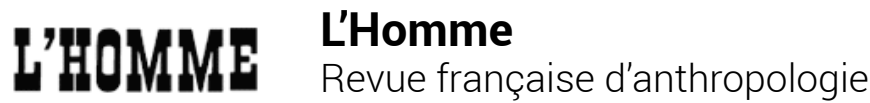

195-196 | 2010

Auto-biographie, Ethno-biographie

\section{Réponse à la réponse de Vincent Debaene}

\section{Emmanuel Désveaux}

\section{(2) OpenEdition}

\section{Journals}

Édition électronique

URL : http://journals.openedition.org/lhomme/22598

DOl : 10.4000/lhomme.22598

ISSN : 1953-8103

\section{Éditeur}

Éditions de l'EHESS

\section{Édition imprimée}

Date de publication : 10 novembre 2010

Pagination : 497-498

ISSN : 0439-4216

\section{Référence électronique}

Emmanuel Désveaux, «Réponse à la réponse de Vincent Debaene », L'Homme [En ligne], 195-196 | 2010, mis en ligne le 04 novembre 2012, consulté le 20 avril 2019. URL : http:// journals.openedition.org/lhomme/22598 ; DOI : 10.4000/lhomme.22598 


\title{
Réponse à la réponse de Vincent Debaene
}

\author{
Emmanuel Désveaux
}

$\mathrm{L}$

E NUMÉRo 193 de L'Homme, première livraison de la revue qui suit la mort de Claude Lévi-Strauss, comporte un hommage à son fondateur. Cet hommage se compose d'un très bel essai scriptuairophotographique, dû à Jean Jamin, actuel directeur de la revue, et deux articles signés respectivement de Françoise Héritier et d'Emmanuel Terray. J'avoue que celui de Terray m'a profondément touché dans la mesure où il signale la réconciliation par la pensée de deux personnalités que j'admire chacune tout particulièrement et dont je me souviens toutefois qu'elles ont pu par le passé s'affronter de façon violente. Ce numéro comporte aussi, immédiatement après ces hommages, et sous la bannière de l'intitulé générique "Débat", un assez long texte de Vincent Debaene (pp. 45-50). Ce dernier se veut une réponse à la recension que j'avais rédigée dans un numéro précédent de L'Homme (2009, I90 : 199-20I) du volume Fuvres de Lévi-Strauss publié dans la collection de La Pléiade sous sa direction, en 2008. Or, évidemment, le texte de Debaene ne me donne pas un très bon rôle, puisque mon manque d'enthousiasme à l'égard de cette Pléiade est interprété d'emblée comme une malveillance foncière.
Comment comprendre autrement la litote "bien peu bienveillante" dont y est qualifiée dès les premières lignes ma recension, oubliant la conclusion qui lui souhaitait quand même "bon vent"? Je mérite peut-être un peu mieux que d'avoir été assigné au rôle de vil imprécateur de l'héritage du maître, au moment même où la profession unanime était encore en deuil de lui. Mais qu'importe. Convenons que les hasards du calendrier font parfois mal les choses. Cela étant, à défaut de restaurer mon honneur, je prends aujourd'hui à mon tour mon droit de répondre à Vincent Debaene. Je ne l'exercerai que sur quelques points.

Vincent Debaene se plaint de ce que j'ironise un peu sur le poids de l'École normale supérieure dans cette édition des Fuvres de Lévi-Strauss, entendue évidemment comme réseau de solidarité entre anciens membres de cette vénérable institution (comment peut-il feindre de ne pas le comprendre ?). J'ai probablement tort car il y a manifestement crime de lèse-majesté à faire la remarque... à moins que ce soit de l'avoir fait avec une touche d'ironie qui ait fait réagir "au quart de tour", comme le dit l'expression populaire, Debaene sur ce thème. 2010, 193:45-50. 
Selon lui toujours, j'aurais indûment attaqué les collaborateurs de cette édition, tout en épargnant Lévi-Strauss lui-même... Et bien en fait, non. Dès lors que je contestai le principe même d'une telle édition annotée, ou à tout le moins son caractère précipité - là-dessus Debaene et moi sommes bien d'accord sur le motif profond de notre désaccord -, il était évident que je reprochai aussi, d'une certaine manière, à Lévi-Strauss d'y avoir consenti. Je ne pense pas que cela ait échappé à aucun des lecteurs de L'Homme, sauf peut-être à Debaene, aveuglé peut-être par le fait que l'on ne fit pas assez l'éloge de son travail. Sur ce dernier point, j'ajouterai simplement ceci : on peut douter que ces mêmes lecteurs aient attendu que je prenne le relais, dans les pages d'une revue professionnelle, du service de presse de la maison Gallimard comme l'avaient fait avec complaisance - mais c'est normal, car c'est leur métier - les journalistes des pages littéraires de Libération, du Monde, du Figaro ou encore de Télérama durant tout le printemps et l'été 2008. En tout cas, le directeur de L'Homme ne devait pas le penser, sinon, vu sa très fine connaissance du milieu intellectuel parisien, il se serait mis en chasse d'un autre recenseur que moi.

Abordons enfin de nouveau la question des photographies, puisqueVincent Debaene y revient et qu'effectivement elle est importante. Imaginons que cette édition compacte ait été faite dans une autre collection - pas nécessairement du reste chez un autre éditeur (voir la collection "Quarto") -, on n'aurait pas été lié à la nécessité d'imprimer sur du papier bible et on aurait eu, mécaniquement, de bien meilleurs résultats. Quant au reste, Debaene s'égare. Je ne vois pas en quoi accuser les éditions Plon d'avoir mis sur le marché depuis les années 1950 des éditions de plus en plus dégradées de Tristes Tropiques au regard de la qualité des repro- ductions photographiques pourrait jouer comme justification du massacre qui s'offre à nos yeux aujourd'hui en la matière avec cette édition de La Pléiade. Dans la logique de son argument, Debaene aurait dû se faire le défenseur d'une réédition digne de ce nom qui aurait cherché à réparer les dégâts commis, plutôt que de les aggraver! Autre solution pour échapper à la malédiction du papier bible, pourquoi ne pas avoir conçu un album Lévi-Strauss, adossé au titre de collection de La Pléiade, comme cela s'est fait par le passé pour d'autres auteurs? Mais c'eût peut-être interféré avec le destin commercial du petit volume illustré Claude LéviStrauss. L'Homme au regard éloigné, que Vincent Debaene et Frédéric Keck publiaient peu après la parution des Fuvres dans la collection "Découvertes", toujours chez Gallimard? Rappelons qu'ils sont également, ensemble ou séparément, les auteurs de nombreux ouvrages de type digest pour les étudiants, de productions audiovisuelles, d'entretiens et autres produits culturels dérivés, sur Lévi-Strauss. De sorte que lorsque Debaene, qui en fut un rouage essentiel dans le cas qui nous occupe, évoque dans sa conclusion la parfaite légitimité de la réappropriation de Lévi-Strauss par I' "industrie culturelle" (je n'aurais personnellement pas osé employer l'expression!) - certes parmi d'autres réappropriations possibles -, je lui réponds simplement que, de mon côté, c'est vrai, je reste attaché à une conception plus artisanale de l'exercice de la réflexion. II est probable toutefois que, sur ce point comme sur le premier soulevé dans cette réponse, je fasse, par les temps qui courent, complètement fausse route. 